
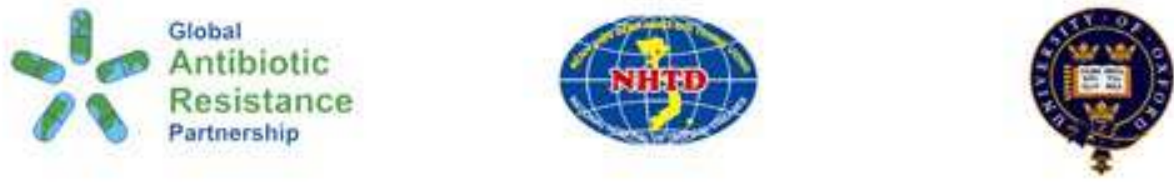

\title{
SITUATION ANALYSIS
}

Antibiotic Use and Resistance in Vietnam

\section{Executive Summary}

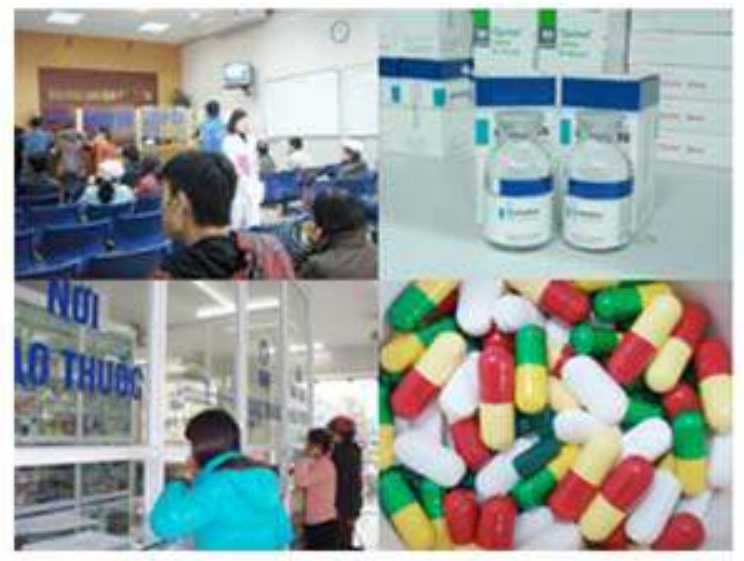

On behalf of the National Working Group.

Nguyen Van Kinh, chairman

Director National Hospital for Tropical Diseases

Hanoi, Vietnam

October 2010

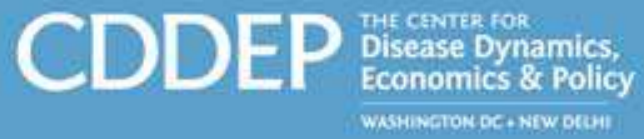




\section{GARP- Vietnam National Working Group}

Nguyen Van Kinh, M.D., Ph.D, Chairman, Director of National Hospital of Tropical Diseases (NHTD), Hanoi

Luong Ngoc Khue, M.D., Ph.D., Director of Medical Services Administration, Ministry of Health

Truong Quoc Cuong, Pharm., Ph.D., Director of Drug Administration, Ministry of Health

Ly Ngoc Kinh, M.D., Ph.D, Medical Services Administration, Ministry of Health

Ngo Thi Bich Ha, Pharm., M.Sc., Officer, Medical Services Administration, Ministry of Health

Hoang Thanh Mai, M.D., Communication expert, Drug Administration, Ministry of Health

Nguyen Hong Ha, M.D., M.Sc., Vice-Director of NHTD

Nguyen Vu Trung, M.D., Ph.D, Ass. Prof., Chief of Clinical Laboratories, NHTD. Deputy Head, Lecturer, Department of Microbiology, Hanoi Medical University, Vietnam

Pham Van Ca, M.D., Ph.D, Ass. Prof., Deputy-manager of Clinical Laboratories, NHTD

Nguyen Thi Kim Chuc, M.D., Ph.D, Ass. Prof., Deputy Head, Lecturer, Department of Family Medicine, Hanoi Medical University

Doan Mai Phuong, M.D., Ph.D, Deputy-manager of Microbiology Department, Bach Mai Hospital, Hanoi

Nguyen Quoc An, D.V.M, Ph.D, Department of Animal Health, Ministry of Agriculture and Rural Development

Tran Tinh Hien, M.D., Ph.D, Prof. Vice-Director Clinical Research, Oxford University Clinical Research Unit, Ho Chi Minh City, Vietnam

Peter Horby, M.D., Director, Oxford University Clinical Research Unit, Hanoi

\section{GARP- Vietnam Staff}

Heiman Wertheim, M.D., Ph.D., GARP-Vietnam Country Supervisor, Oxford University Clinical Research Unit

Do Thi Thuy Nga, Pharm., M.Sc., GARP-Vietnam Country Coordinator, Oxford University Clinical Research Unit

\section{CDDEP GARP Secretariat}

Ramanan Laxminarayan, Ph.D. MPH, GARP Principal Investigator, Senior Fellow and Director, Center for Disease Dynamics, Economics and Policy

Hellen Gelband, MHS, Program Fellow and Study Coordinator, Center for Disease Dynamics, Economics and Policy 


\section{Foreword}

The global problem of antimicrobial resistance is particularly pressing in developing countries, where the infectious disease burden is high and cost constrains the replacement of older antibiotics with newer, more expensive ones. Gastrointestinal, respiratory, sexually transmitted, and nosocomial infections are leading causes of disease and death in the developing world, and management of all these conditions has been critically compromised by the appearance and rapid spread of resistance.

There is little doubt that the more exposure bacteria have to any antibiotic-the greater the "drug pressure"- the more likely it is that resistant strains will arise and spread. Antibiotic drug pressure is the single most important factor promoting development of drug resistance in bacteria. However, reasons for drug pressure are multi-factorial. Although drug resistance is primarily a medical problem, the causes of resistance-at least the pace of escalation-are ecological, epidemiological, socio-cultural and economic. Patients, physicians, veterinarians, clinics and hospitals, and retailers-from large pharmacies to local drug sellers-have little motivation (economic or otherwise) to weigh the negative impact of their use of antibiotics on others, especially those in the future. Standard responses, such as increasing surveillance and launching public information campaigns on the hazards of resistance-while being a necessary part of an overall policy response-may have limited impact on their own. In order to work, policy solutions must alter incentives for patients, physicians, and others in the health care system to act in society's best interests. Evaluating policy solutions involves understanding infectious diseases in populations. Research on evaluating focused, context-specific policy solutions that are likely to have a significant impact on resistance is a first step. Translating these policy solutions to policy action is the second.

Antibiotic resistance currently does not top any list of national problems. Strategies to control antibiotic resistance should not drain resources from more pressing concerns. Done correctly, controlling antibiotic resistance should be either cost neutral or in fact, be one of the few health interventions that actually save money.

Here we present the situation analysis of antibiotic use and resistance in Vietnam. We used international papers, local papers and reports, and expert interviews to complete this analysis. This report gives insight into interventions that can be targeted to control inappropriate antibiotic use and resistance in Vietnam, while taking care not to diminish access to these, at times lifesaving, drugs.

\section{Dr. Nguyen Van Kinh}

Chairman, on behalf of the GARP - Vietnam National Working Group 


\section{Executive Summary}

The Global Antibiotic Resistance Partnership (GARP) aims to address the challenge of antibiotic resistance by developing actionable policy proposals in Vietnam and four other low- and middle-income countries: China, India, Kenya, and South Africa. GARP will develop the evidence base for policy action on antibiotic resistance and identify policy opportunities where research, advocacy, and information have the best chance of slowing the development and spread of resistance.

Since the initiation of doi moi reforms in 1986, Vietnam has experienced many positive changes: an increase in incomes and life expectancy, decreased childhood mortality, and improved access to health care and drugs, including antibiotics. Access to antibiotics has brought with it an uninvited but not unexpected guest, antibiotic resistance. Nevertheless, opportunities to conserve the value of antibiotics and improve the outlook for patients are still open.

In 1996, the MoH issued the National Drug Policy, which states, "Antibiotics are very important drugs in treatment, and therefore it is necessary to regulate the prescription, antibiotic use, and antibiotic resistance of most common bacterial pathogens as well as improve laboratory diagnosis." This policy statement is even more relevant today, in 2010 .

\section{The Global Problem of Antibiotic Resistance}

Around the world, bacterial pathogens are becoming ever more resistant to antibiotics. The first-generation antibiotics are already of little use in many circumstances. Newer antibiotics are more expensive, and now even some last-resort antibiotics are losing their effectiveness. Recent evidence is the spread of carbapenem-resistant bacteria (ndm-1) in several countries in Asia and Europe. Like other shared resources, the effectiveness of antibiotics should be viewed as a precious commodity, to be protected and valued, not squandered through unnecessary use. The goal is that antibiotics be used only for bacterial infections that need to be cured by antibiotics.

\section{Antibiotic Resistance in Vietnam}

- Vietnam already experiences high levels of antibiotic resistance. In recent years, individual studies have reported the following: 
- Vietnam had the highest prevalence of penicillin-resistant (71.4 percent) and erythromycin-resistant (92.1 percent) Streptococcus pneumoniae - a very common cause of respiratory infections-of the 11 countries in the Asian Network for Surveillance of Resistant Pathogens (ANSORP) in 2000-2001.

- 75 percent of pneumococci are resistant to three or more classes of antibiotics.

- 57 percent of the samples of another common bacterial pathogen, Haemophilus influenzae, from children in Hanoi were resistant to ampicillin in 2000-2001. Similar rates were found in Nha Trang.

- Bacteria cultured from children with diarrhea are highly resistant. In most cases, oral rehydration therapy is the best treatment for diarrhea, yet one-quarter of children had been given an antibiotic before they got to hospital.

- Resistance is common among gram-negative bacteria (enterobacteriaceae): more than 25 percent of isolates tested in a Ho Chi Minh City hospital were resistant to third-generation cephalosporins in 2000-2001. A study published in 2009 reported that 42 percent of gram-negative bacteria were resistant to ceftazidime, 63 percent to gentamicin, and 74 percent to nalidixic acid in both the hospital and the community.

- Resistance is increasing. In the early 1990s in Ho Chi Minh City, 8 percent of pneumococcus isolates were resistant to penicillin. By 1999-2000, this had risen to 56 percent. Similar trends were seen in northern Vietnam.

Because of the high rates of resistance, many antibiotic regimens recommended in current treatment guidelines are unlikely to be effective. Because infectious diseases remain common in Vietnam, access to effective antibiotics is extremely important. The increasing resistance rates in Vietnam are now jeopardizing the overall effectiveness of antibiotic treatment.

\section{Drivers of Antibiotic Use and Antibiotic Resistance}

The more antibiotics are used, the more antibiotic-resistant organisms will spread. Antibiotics are overused both in the community-by people buying antibiotics after self-diagnosis or on the advice of a health-care provider-and in the hospital, where antibiotics may substitute for better infection control, broad-spectrum antibiotics may be used instead of narrow-spectrum drugs, and people may 
be given newer, expensive branded antibiotics instead of less expensive first-line generic products.

Some of the reasons for inappropriately high antibiotic use in Vietnam are discussed below.

\section{In the Community}

Out-of-pocket health-care expenditures. User fees at public hospitals, health insurance schemes, the commercialization of the pharmaceutical industry, and the deregulation of the retail trade in drugs have led to significant improvements in the quality and accessibility of health care. However, they have also increased out-ofpocket health expenditures as a proportion of total health expenditures. The high out-of-pocket expenditures encourage people to bypass providers and purchase drugs-including antibiotics-directly, without proper diagnosis. Total drug sales have nearly tripled in value between 2001 and 2008, from USD\$500 million to USD \$1,400 million. No separate figures are available, but antibiotics are among the most widely used drugs, and they are often used inappropriately.

Purchases without prescription. Even though prescriptions are legally required, antibiotics (and a wide range of other drugs) can be purchased directly by consumers at pharmacies or drug outlets. Self-diagnosis is not very accurate, but self-treatment is very common. In a community-based study undertaken in 2007, 78 percent of antibiotics taken by the study participants were purchased in private pharmacies without prescriptions. Buying drugs directly is cheaper and faster than going to a practitioner.

Lack of knowledge about appropriate antibiotic use. A 2007 study evaluated knowledge about antibiotic use in rural Vietnam. Despite the existence of guidelines, knowledge about antibiotic use was poor, and health-care providers often dispensed antibiotics inappropriately, for common colds and coughs. The type, dosage, and duration of treatment often did not comply with the guidelines for antibiotic use.

\section{In Hospitals}

Inadequate infection control and overcrowding. Good infection control is essential to prevent the further spread of resistant bacteria. Hospitals are overcrowded, however, often with more than one patient in a bed, and waste management is suboptimal.

Lack of adequate microbiology services. Most hospitals do not have mi- 
crobiology laboratories. Existing laboratories operate without requirements for internal and external quality assessments. Well-trained clinical microbiologists to improve laboratory quality are scarce. Data on resistance in Vietnam can therefore not be considered accurate.

Lack of effective drug and therapeutics committees. In 1997, the MoH requested that every hospital establish a drug and therapeutics committee to implement guidelines for drug use, give professional advice for rational antibiotic therapy, list the drugs commonly used in the hospital, inform its health-care workers about appropriate drug use, and organize antibiotic drug resistance monitoring and reporting. All central hospitals have such committees, but not all have credentialed pharmacists or microbiologists, and their resources are limited. Most lowerlevel health-care centers have no drug and therapeutics committees.

\section{In Agriculture}

Antibiotic use is widespread in farm animals and aquaculture for growth promotion and infection prophylaxis and treatment. Pigs and poultry are supplemented with tetracycline and tylosin. Farmed shrimp, crabs, and fish are given quinolones and sulfonamides in concentrations several times higher than recorded in other countries. As a result, antibiotic residues are commonly found in land and sea animals raised in Vietnam, although most levels are within legal limits and most of the residues are of allowed antibiotics.

There are other signs of excessive antibiotic use. One survey showed that raw foods, including meat and shellfish, were contaminated with multidrug-resistant Salmonella. Campylobacter isolated from chickens has particularly high levels of resistance: 90 percent of isolates are resistant to nalidixic acid, 89 percent to tetracycline, and 82 percent to ciprofloxacin.

\section{GARP-Vietnam Research}

One of the aims of GARP-Vietnam is to fill information gaps, and the GARP-VN National Working Group is currently undertaking several projects:

1. Creating a senior peer network on antibiotic use and resistance. Information-sharing channels will be established among several leading hospitals in collaboration with the Drug Administration. Approximately 20 hospitals will submit data to $\mathrm{MoH}$ regarding antibiotic use and resistance in their hospitals, and regular reports will be issued. 
2. Assessing the economic burden of resistance. The most powerful argument for policymakers is that resistance costs money, whereas antibiotic stewardship may save both money and lives. A study will assess current resistance levels of common bacteria cultured from blood and cerebrospinal fluid. The effect of resistance on the costs of antibiotic treatment will be compared with a baseline of antibiotic treatment before the emergence of resistance.

3. Assessing the economic incentives for selling antibiotics at community pharmacies. Questionnaires and direct observations of drug selling will be conducted in 15 rural and 15 urban pharmacies. The profitability of antibiotic sales for pharmacies will be estimated.

\section{Opportunities for Controlling Antibiotic Resistance}

\begin{tabular}{ll}
\hline Policy option & Action \\
\hline $\begin{array}{l}\text { Antibiotics are pre- } \\
\text { scription only drugs. }\end{array}$ & Develop national action plan for antibiotic resistance. \\
$\begin{array}{l}\text { Make antibiotics } \\
\text { prescription-only }\end{array}$ & Enforce current law. \\
$\begin{array}{l}\text { Make hospitals' drug } \\
\text { and therapeutics com- } \\
\text { mittee } \\
\text { effective }\end{array}$ & $\begin{array}{l}\text { Enforce requirement for committees, define their func- } \\
\text { tions and standards, and develop audit mechanisms. Give } \\
\text { committees tools and guidance on antibiotic stewardship. }\end{array}$ \\
$\begin{array}{l}\text { Establish infection- } \\
\text { control } \\
\text { committees in hospi- } \\
\text { tals }\end{array}$ & $\begin{array}{l}\text { Provide up-to-date, accurate resistance data. } \\
\text { activities and improve infrastructure. Establish standard- } \\
\text { ized indicators to monitor progress, such as hospital- } \\
\text { acquired infection rates by department and hand-washing } \\
\text { compliance. }\end{array}$ \\
$\begin{array}{l}\text { Track national antibi- } \\
\text { otic resistance }\end{array}$ & $\begin{array}{l}\text { Develop national testing and quality control guidelines. } \\
\text { Fund resistance testing, quality control, training, and } \\
\text { reporting. Issue annual national report on both antibiotic } \\
\text { use and resistance. }\end{array}$ \\
$\begin{array}{l}\text { Monitor antibiotic use } \\
\text { in hospitals }\end{array}$ & $\begin{array}{l}\text { Standardize antibiotic usage indicators to international } \\
\text { units (e.g., defined daily dosage per I00 bed-days). Issue } \\
\text { annual national report on both antibiotic use and resis- } \\
\text { tance }\end{array}$ \\
$\begin{array}{l}\text { Develop curriculum } \\
\text { for } \\
\text { medical and pharmacy } \\
\text { schools }\end{array}$ & $\begin{array}{l}\text { Teach and train professionals on antibiotic resistance and } \\
\text { appropriate antibiotic use. }\end{array}$ \\
\hline
\end{tabular}


Develop treatment guidelines

Establish pharmacovigilance center

Conduct public education campaign

Set up vaccination programs

Enhance laboratory capabilities

Curb antibiotic use in agriculture
Ensure timely and evidence-based updates of treatment guidelines for infectious diseases.

Engage pharmacovigilance center in curbing inappropriate antibiotic prescribing.

Create awareness and educate Vietnamese public about appropriate and inappropriate antibiotic use.

Achieve high vaccination coverage for communicable diseases to prevent bacterial infections that require antibiotic treatment.

Ensure quality laboratory testing. Consider establishing national reference center (center of excellence) for antibiotic resistance testing. Create network for sharing data, guidelines, and expertise.

Enforce current law. Set up national antibiotic use and resistance surveillance system. Issue annual national report on both antibiotic use and resistance. Develop regulations on antibiotic use before harvesting.

Vietnam's many opportunities to control and reverse antibiotic resistance will be fully analyzed in the final GARP-VN report, to be completed in spring 2011. Policy options-some more promising than others-are listed below. The working group will assess these options by estimating their costs, human resource and technical feasibility, time frame for implementation, and likely effects in Vietnam. A short list of the most promising policy options will then be recommended.

This first-situation analysis on antibiotic resistance in Vietnam introduces an important issue to all stakeholders-government, pharmacies, doctors, clinics, nongovernmental agencies, the pharmaceutical industry, and patients. We are all responsible for addressing the problem, and concerted action is needed to maintain the effectiveness of antibiotics while ensuring access to these life-saving drugs.

\section{On behalf of the National Working Group,}

Nguyen Van Kinh, chairman

Director National Hospital for Tropical Diseases
Hanoi, Vietnam 